\title{
Isolation and Molecular Characterization of Escherichia coli from Goat of Apparently Healthy and Clinical Cases
}

\author{
Abu Sayeed M Abdullah', ${ }^{1}$ M Shahidur Rahman Khan ${ }^{1}$, Munirul Alam², Farjana Haq ${ }^{1}$, Jayedul Hassan ${ }^{1}$ \\ ${ }^{1}$ Department of Microbiology and Hygiene, Faculty of Veterinary Science, Bangladesh Agricultural University, Mymensingh - 2202, Bangladesh, \\ ${ }^{2}$ Enteric Microbiology laboratory, ICDDR'B, Mohakhali, Dhaka - 1212
}

(Received 22 November 2009; Accepted 21 August, 2010)

\begin{abstract}
The prevalence of $E$. coli in faecal sample of apparently healthy and clinical cases of goats was investigated. A total of 150 samples of which 90 from clinical cases and 60 from apparently healthy goat were examined. Among the samples examined, 65(72.22\%) and 25(41.67\%) were found to be positive for $E$. coli in clinical and healthy cases respectably. The banding pattern of chromosome of isolated $E$. coli from goats of apparently healthy and clinical cases was also carried out by Pulsed Field Gel Electrophoresis through which the clonal relation between the isolated $E$. coli was studied. Chromosomal banding pattern of $E$. coli from goat of apparently healthy cases from same and different location were found identical which indicates similar clonal origin of $E$. coli. On the other hand, banding pattern of $E$. coli chromosome from diseased goat of different location were found dissimilar which may be either due to difference in origin of $E$. coli clone or phage encoded chromosome which can muted $E$. coli isolates. Thus it can be concluded that Pulsed Field Gel Electrophoresis profile varies according to severity of the disease.
\end{abstract}

Keywords: Goat, E. coli, Isolation, Molecular Characterization

\section{Introduction}

Escherichia coli (E. coli) is an enteric bacilli, Gram-negative, rod shaped, motile, capsulated, flagellated, oxidase negative, lactose fermenter, non-acid fast, non spore former facultative anaerobes and remains as commensal in the lower intestine of human and animal $^{1-3}$ 11,14,17. The populations of E. coli O157:H7 detected in goat fecal samples from meat goatherds ranged from 3 to $87 \%$ and may be a potential primary source for E. coli 0157: H7 contamination of goat meat products from fecal contamination ${ }^{4}$.

Systemic infection caused by $E$. coli in kits resulting in septicemia and enteritis, characterized by fever, anorexia, and weakness, followed by coma and death which is similar to colibacillosis in calves $^{5}$. Shiga-like toxins produced by E. coli damage the endothelial cells in the kidneys, pancreas, brain, and other organs, thus inhibiting those organs ability to function ${ }^{6-7}$.

In 1984, Schwartz and Cantor described Pulsed field gel electrophoresis (PFGE), introducing a new way to separate DNA ${ }^{8}$. In particular, PFGE resolved extremely large DNA for the first time, raising the upper size limit of DNA separation in agarose from 30-50 kb to well over $10 \mathrm{Mb}(10,000 \mathrm{~kb})$. PFGE gel images were retrieved and aligned to generate a composite image containing the banding profiles of all the isolate. The image was analyzed by the Diversity Database Finger printing software version 2.2.0 (Bio-Rad) to assess relatedness between strains. However, the present research work was undertaken with the
Isolation, Identification and Biochemical characterization of goat E. coli and application of PFGE technique for genomic organization and comparative study of PFGE using the isolates of $E$. coli from apparently healthy and clinical cases.

\section{Materials and Methods}

This study was conducted during the period of November 2006 to October 2007 in the Department of Microbiology and Hygiene, Faculty of Veterinary Science, Bangladesh Agricultural University (BAU), Mymensingh and in the laboratory of the Enteric Microbiology, International Center for Diarrheal Disease Research, Bangladesh (ICDDR,B), Mohakhali, Dhaka.

\section{Collection and transportation of samples}

A total of 150 faecal samples were collected from different selected areas of Mymensingh district. Ninety of 150 faecal samples were collected from goats with the symptom of diarrhea and 60 were collected from apparently healthy goats (Table 1). All the samples were collected with the help of sterile cotton bud. Samples were immediately transferred to sterile nutrient broth in sterile screw capped test tubes.

Cultural, morphological and biochemical examination of samples

The collected samples were primarily cultured onto Nutrient broth (NB) and then pure culture was performed on Eosin Methylene Blue (EMB) agar, Salmonella-Shigella (SS) agar, MacConkey (MC) agar, Brilliant Green (BGA) agar and Blood agar (BA) following 
the procedure described by Carter $^{9}$. Individual colony was picked up, stained with Gram stain and the morphological study was performed following the procedure described by Cowan ${ }^{10}$. The motility test was performed to differentiate motile bacteria from the non-motile one. Upon cultural examination the isolated organism was subjected to different biochemical tests (sugar fermentation test, indole production test, MR-VP test, citrate utilization test ${ }^{11}$ ).

\section{Maintenance of stock culture}

For maintenance of stock culture, pure culture of the isolated $E$. coli was stored on soft agar media. After preservation of E. coli strains in soft agar, 20 and 10 strains were selected from diarrheic and apparently healthy goats, respectively. These were then carried through icebox to the enteric microbiology laboratory in ICDDR, B and preserved in soft agar after giving Lab. Identity mark (Table 1).

\section{Molecular characterization}

PFGE was performed with the Contour Clamped Homogenous Electric Field (CHEF-DRII) apparatus from the Bio-Rad laboratories. It was ensured that the gel was covered by about 2 mm of running buffer. The temperature and the flow rate of the running buffer were adjusted to $140^{\circ} \mathrm{C}$ and 0.75 liter per minute, respectively. Electrophoresis was done at 6 volts for $18 \mathrm{~h}$. Then the gel was stained with ethidium bromide $(0.5 \mathrm{ig} / \mathrm{ml})$ solution for 30 minutes at room temperature and then de-stained in sufficient distilled water for 1 hour. The gel was visualized on the UV transilluminator and photographs were taken as described previously. The DNA size standards used was the Salmonella serotype Braenderup ranging from 20.5 to 1135 KB.

\section{Image analysis}

The fingerprint pattern in the gel was analyzed using a computer software package, Quantity One version 3.0 (Applied Math's BVBA, Belgium). After background subtraction and gel normalization, the similarity among the strains was determined using the Dice coefficient and the fingerprint patterns were subjected to cluster analysis using the Unweighted Pair Group Method with Arithmetic Mean (UPGMA). The enzyme (Xba1) restriction digestion restricted chromosomal genome into 12 to 19 fragments. For cluster analysis, only fragments having a molecular weight of $28.8 \mathrm{~KB}$ and above were considered.

Table 1. Source, place and date of isolation of Escherichia coli strains and Lab. Identity.

\begin{tabular}{|c|c|c|c|}
\hline Source (Rectal swab) & Place of isolation & Date of isolation & Lab. Identity \\
\hline Goat (Apparently healthy) & BAU goat farm & 05/ 07/ 2007 & $\mathrm{G} 4 \mathrm{Fb}$ \\
\hline Goat (Apparently healthy) & BAU goat farm & 08/ 07 /2007 & $\mathrm{G} 5 \mathrm{~F} \mathrm{a}$ \\
\hline Goat (Apparently healthy) & BAU goat farm & 08/ $07 / 2007$ & G $5 \mathrm{~F} \mathrm{~b}$ \\
\hline Goat (Apparently healthy) & Boyra, Mymensingh & $23 / 07 / 2007$ & G $6 \mathrm{CP}$ a \\
\hline Goat (Apparently healthy) & Boyra, Mymensingh & $23 / 07 / 2007$ & G 6 CP b \\
\hline Goat (Apparently healthy) & Boyra, Mymensingh & $23 / 07 / 2007$ & G 6 CP c \\
\hline Goat (diarrheic) & BAU goat farm & $10 / 07 / 2007$ & $\mathrm{G} 8 \mathrm{~F} \mathrm{a}$ \\
\hline Goat (diarrheic) & BAU goat farm & $10 / 07 / 2007$ & $\mathrm{G} 10 \mathrm{~F} \mathrm{~b}$ \\
\hline Goat (diarrheic) & BAU goat farm & $10 / 07 / 2007$ & G $10 \mathrm{~F} \mathrm{c}$ \\
\hline Goat (diarrheic) & Boyra, Mymensingh & $23 / 07 / 2007$ & G 3 CP a \\
\hline Goat (diarrheic) & Boyra, Mymensingh & $23 / 07 / 2007$ & G 3 CP b \\
\hline Goat (diarrheic) & Boyra, Mymensingh & $23 / 07 / 2007$ & G 3 CP c \\
\hline Goat (diarrheic) & Boyra, Mymensingh & 26/ 07/ 2007 & G 9 CP a \\
\hline Goat (diarrheic) & Boyra, Mymensingh & 26/ 07/ 2007 & G 9 CP b \\
\hline Goat (diarrheic) & Boyra, Mymensingh & $26 / 07 / 2007$ & G 9 CP c \\
\hline Goat (diarrheic) & BAU Veterinary clinics & 28/07/ 2007 & $\mathrm{G} 3 \mathrm{Cl}$ a \\
\hline
\end{tabular}


Abdullah et al.

Table 2. Demonstration of approximate number of band of Escherichia coli formed by restriction enzyme as a result of pulsed field gel electrophoresis.

\begin{tabular}{|c|c|c|c|c|c|}
\hline \multicolumn{2}{|l|}{ Species } & Sources & Lab. ID & $\begin{array}{c}\text { Restriction } \\
\text { Enzyme }\end{array}$ & $\begin{array}{l}\text { Approximate no. of } \\
\text { restriction fragment }\end{array}$ \\
\hline \multirow[t]{6}{*}{ Goat } & Apparently healthy & BAUGF & $\mathrm{G} 4 \mathrm{Fa}$ & Xba 1 & 15 \\
\hline & & BAUGF & $\mathrm{G} 5 \mathrm{~F} \mathrm{a}$ & Xba 1 & 15 \\
\hline & & $\mathrm{BM}$ & G 6 CP a & Xba 1 & 15 \\
\hline & & $\mathrm{BM}$ & G 9 CP c & Xba 1 & 14 \\
\hline & & BAUVC & G $3 \mathrm{Cl}$ c & Xba 1 & 19 \\
\hline & Marker & Not $^{2}$ & 15 & & \\
\hline
\end{tabular}

BAUGF = Bangladesh Agricultural University Goat Farm; BM = Boyra, Mymensingh; BAUVC = Bangladesh Agricultural University Veterinary Clinics; Marker = Salmonella braenderup

\section{Results and Discussion}

Isolation and identification result of the study indicated that the faecal sample contained Gram negative and motile organisms. Colony character on EMB agar, MacConkey agar, Salmonella-Shigella agar, Brilliant Green agar and fermentation ability of five basic sugars indicates that the bacterium was $E$. coli which was similar to the findings of Beutin et al. and Mckec et al. ${ }^{12-13}$.

In Gram's staining, the morphology of the isolated bacteria exhibited pink, small rod shaped Gram negative bacilli and in the hanging drops technique all the isolates revealed motile. These findings were supported by several authors ${ }^{14-16}$. The result of Catalase, MR and indole test of E. coli isolates were positive but $\mathrm{V}$-P test and Citrate test were negative as reported by Buxton and Fraser $^{14}$.

The prevalence of $E$. coli infection was found higher in diarrheic goats $(72.22 \%)$ compared to that of apparently healthy goats (41.67\%).

Six-selected E coli from goat of apparently healthy (3) and clinical cases (3) were allowed for Pulsed field gel electrophoresis (PFGE). PFGE analysis of the Xba1 digested chromosomal DNA of the Escherichia coli strains yielded 12 to 19 reproducible DNA fragments ranging in size approximately from $>20 \mathrm{kB}$ to $<1135 \mathrm{~KB}$ (Table 2). Three isolated $E$. coli from apparently healthy goats (G4Fa, G5Fa, G6CPa) were clonal with identical banding patterns from same and different locality which either indicating that they were probably of the same clonal origin or this probably indicates genetic relatedness ${ }^{17}$ but $E$. coli from goats of clinical cases (G8Fc, G9CPc, G3Clc) were clonal with different banding patterns from different locality which indicating that isolates are clonally difference from each other (Fig. 1).

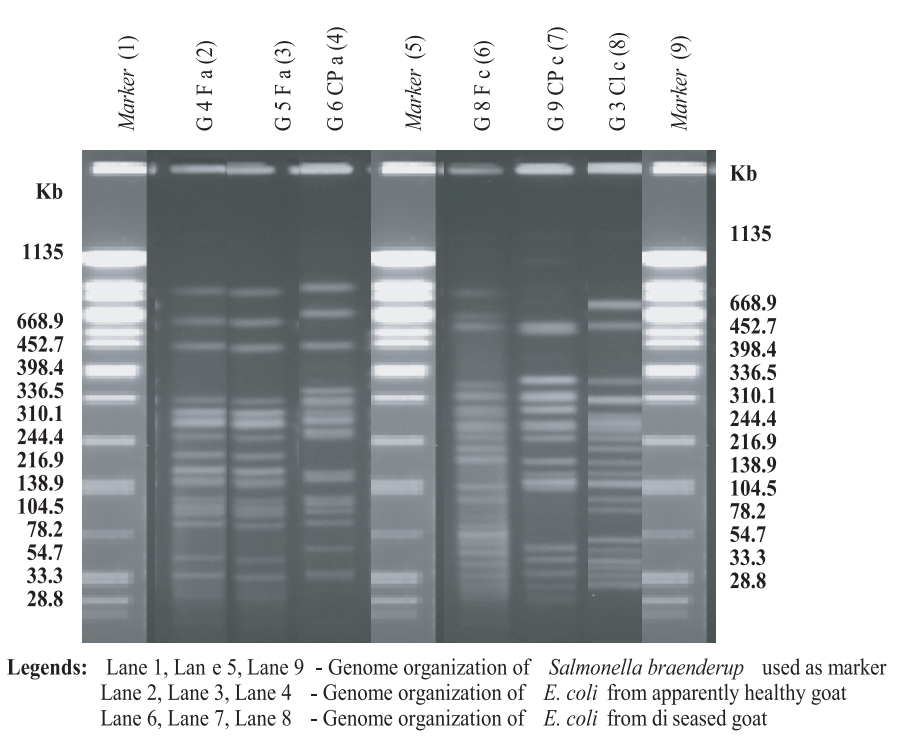

Fig. 1. PFGE pattern of Xba 1 digested representative Escherichia coli isolates from goat of apparently healthy and clinical cases, duck, and pigeon and Not-I digested Salmonella braenderup strains used as marker.

\section{References}

1. Levine MM. 1984. Escherichia coli infections. Germander (ed.), Bacterial vaccines, Academic press, Inc, New York. pp: 187-235.

2. Pelczar JR. Michel J. Krieg NR. and Chan ECS. 1986. Microbiology, $5^{\text {th }}$ edn., pp 272.

3. Thomas AR, Bruce AD, Stacy A, Genagon NM, Warholic UM, Patrick D, Pawlicki JM, Beanan RO, Bruce AH and Paul RK. 2005. E. coli virulence factor hemolysin induces neutrophil apoptosis and necrosis/ lysis in vitro and necrosis/lysis and lung injury in a rat pneumonia model. Am J Physiol Lung Cell Mol Physiol. 289: 207-216.

4. Mobley R, Madden U and Walter AB. 2004. Detection of Escherichia Coli O157: H7 in Fecal Samples in Goats Meat. Questia J Article. 124:

5. Löliger HC. 1970. Pelztierkranheiten. Veb Gustav Fischer Verlag. Jena. pp. 67-72. 
6. Koch R. 2002. Isolation of a lysogenic bacteriophage carrying stx-1 gene, which is closely, associated with Shiga toxin producing E. coli Strains from sheep and human. J Cli Microbiol. 39: 3992-8.

7. Rajib K, Raj P, Bhan MK, Srivastva R, Bhandari N and Arora NK. 1990. Human enterocyte adhesion of enteroadherent Escherichia coli. Indian J Med Res. 91: 368-371.

8. Schwartz DC and Cantor CR. 1984. Separation of yeast artificial chromosome-sized DNAs by pulsed field gradient gel electrophoresis. Cell. 37: 67-75.

9. Carter GR. 1986. Essentials of Veterinary Bacteriology and Mycology. $3^{\text {rd }}$ edn. pp. 312-330.

10. Cowan ST. 1985. Biochemical behavior of E. coli. J Gen Microbiol. 8: 391.

11. Cheesbrough M. 1985. Medical laboratory manual for tropical countries. Vol.10. Microbiology. pp. 250-280.

12. Beutin L, Geier D, Steinruck H, Zimmermann S and Scheutz F. 1993. Prevalence and some properties of verotoxin (Shiga like toxin)producing Escherichia coli in seven different species of healthy domestic animals. J Cli Microbiol. 31: 2483-2488.
13. McKec IA, Melton CAR, Moxley RA, Fancis DH and Brien OAD. 1995. Enterohaemorrharic E. coli O157: H7 requires intimin to colonize the gnotobiotic pig intestine and to adhere to HEP-2 cells. Infect and Immunol. 63: 3739-44.

14. Buxton A. and Fraser G. 1987. Escherichina coli. In. Animal Microbiology. Blackwell Scientific Publications, Oxford, London, Edinburg, Melbourne. Vol.1.

15. Freeman BA. 1985. Burrows Testbook of Microbiology. $22^{\text {nd }}$ edn. In: W. B. Saunders Company, London, Toronto, Mexico city, Rio de Janerio, Tokyo. pp: 464-475.

16. Jones TO. 1987. Intramammary antibiotic preparation and cephalosporins resistance in Salmonella typhinurium 204c. Veterinary Records. 120: 399-400.

17. Alam M, Hasan NA, Ahsan S, Pazhani GP, Tamura K, Ramamurthy T, Gomes DJ, Rahman SR, Islam A, Akter F, Shinoda S, Watanabe H, Faruque SM and Nair GB. 2006. Phenotypic and Molecular characteristics of Escherichia coli isolated from aquatic environment of Bangladesh. Microbiol and Immunol. 50(5): 359-370. 